\title{
The Experimental Method of Crack Detection in Shaft of Rotor System
}

\author{
Ojo Kurdi ${ }^{1,2}$, Ikmal Hakim Bin Hasnan ${ }^{1}$, M. A. Mat Norman ${ }^{1}$, and Ian Yulianti ${ }^{3}$
}

\begin{abstract}
Cracks issues become more important agenda in industrial and building sectors. A crack shaft is one of the common defects in the rotor arrangement and early detection of this failure mode is a really serious thing. The aim of this research was to examine the dispute in the dynamic properties between multiple cracked and un-cracked shaft includes frequency response and natural frequency by experimental procedures using 6-channel analyzer systems. The experiment was carried out on a shaft under un-cracked and also cracked condition with the several depth of crack. The analysis was performed along a circular mild steel shaft with linear solid behavior in which considered six conditions of parameters including un-cracked, first cracked, second cracked, third cracked, fourth cracked, and fifth cracked. Free-free boundary condition was applied into model. The natural frequencies $(\mathrm{Hz})$ obtained from experimental were analyzed and assessed.
\end{abstract}

Keywords - Depth of crack, Vibration, Natural frequency

\section{INTRODUCTION}

$\mathrm{N}$ OWADAYS, either small or large machinery is used every day and has become important to the industrial and construction sectors. These machines will produce vibration either in low or high frequency. The presence of the crack will bring great risk of collapse. A crack has become one of common defect over the years and early detection of this failure mode is a very serious matter[1]. A significant amount of previous research involving detection of transverse crack in rotating shaft by vibration monitoring has been done over the years[2,3,4,5].

Using specific way, the vibration data can be collected and will be useful in order to predict the dynamic behavior of the machines[6][7]. This paper will present a method of collecting data using specific software and instruments to investigate the changes of natural frequency caused by the present of crack on the shaft.

\footnotetext{
${ }^{1}$ Mechanical Engineering Department, Faculty of Engineering, Universiti Selangor, Jalan Timur Tambahan, Bestari Jaya, Selangor Darul Ehsan, Malaysia.

${ }^{2}$ Mechanical Engineering Department, Faculty of Engineering, Universitas Diponegoro, Jalan Prof Sudharto, Tembalang, Semarang, Central Java, Indonesia

${ }^{3}$ Physics Department, Faculty of Mathematics and Natural Sciences, Universitas Negeri Semarang Kampus Sekaran, Central Java, Indonesia
}

\section{II.EXPERIMENTAL SETUP AND INSTRUMENTATION}

This section discussed the process in determining the dynamic characteristic of the mild steel circular shaft. The specimen will be prepared to be used in experimental procedures. Note that two pieces of rubber strings is being used to approximate and provide reasonably free-free end condition for the specimen. Table 1 and Table 2 shows all the parameters for shaft and disc.

TABLE I

DIMENSIONS AND MATERIAL PROPERTIES OF THE SHAFT

\begin{tabular}{|l|l|}
\hline \multicolumn{1}{|c|}{ Parameters } & \multicolumn{1}{c|}{ Units } \\
\hline Length, $\mathrm{L}$ & $0.5 \mathrm{~m}$ \\
\hline Radius, $\mathrm{R}_{\mathrm{s}}$ & $0.01 \mathrm{~m}$ \\
\hline Density, $\rho$ & $7800 \mathrm{~kg} / \mathrm{m}^{3}$ \\
\hline Young Modulus, $\mathrm{E}$ & $2 \times 10^{11} \mathrm{~Pa}$ \\
\hline Unbalanced Mass, $\mathrm{m}_{\mathrm{u}}$ & $1 \times 10^{-4} \mathrm{~kg}$ \\
\hline Distance from center of gravity & $0.2 \mathrm{~m}$ \\
\hline
\end{tabular}

TABLE II

DIMENSIONS AND MATERIAL PROPERTIES OF THE DISC

\begin{tabular}{|l|l|}
\hline \multicolumn{1}{|c|}{ Parameters } & \multicolumn{1}{c|}{ Units } \\
\hline Inner Radius, $\mathrm{R}_{1}$ & $0.01 \mathrm{~m}$ \\
\hline Outer Radius, $\mathrm{R}_{2}$ & $0.2 \mathrm{~m}$ \\
\hline Width, $\mathrm{h}$ & $0.02 \mathrm{~m}$ \\
\hline Density, $\rho$ & $7800 \mathrm{~kg} / \mathrm{m}^{3}$ \\
\hline Position of Disc, $\mathrm{l}_{1}$ & $\mathrm{~L} / 3$ \\
\hline
\end{tabular}

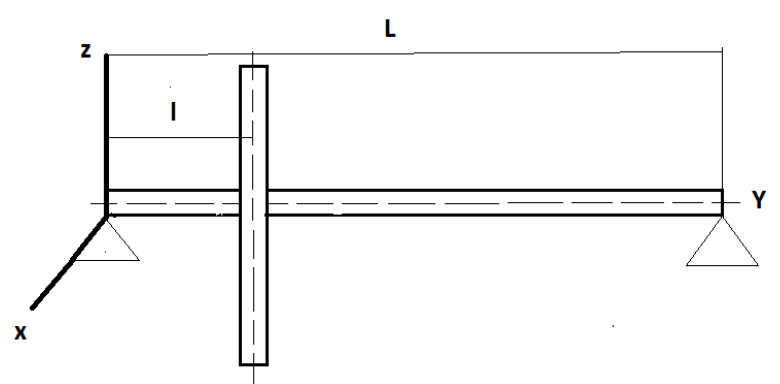

Fig. 1 Simple model rotor system 


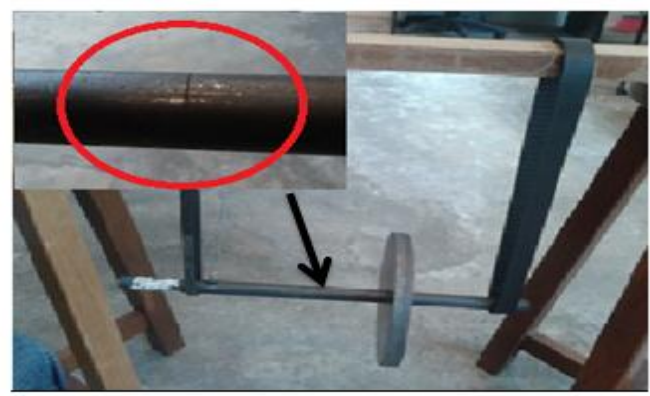

Fig. 2 Experimental equipment

The instruments used for this experimental analysis that to measure the natural frequencies are Fast Fourier Transform (FFT) analyzer, accelerometer, impact hammer and related accessories. Accelerometer along with FFT analyzer is used to acquire the vibration signals. The accelerometer is connected to channel no.5 of FFT analyzer. The impact hammer is used to excite the shaft whose frequency response function has to be captured. For every test, the location of impact hammer is kept constant. Impact hammer has the range of excitation 1$4000 \mathrm{~Hz}$. The shaft is tapped gently with the impact hammer.

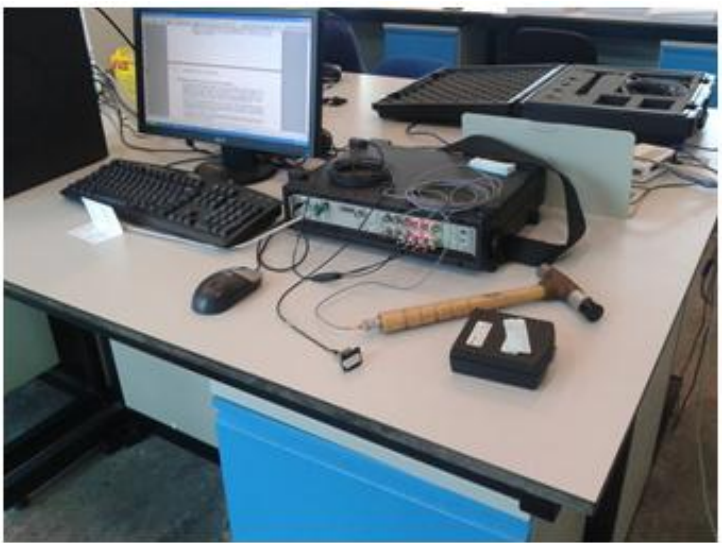

Fig. 3 6-Channel Spectrum Analyzer

1. Pulse Labshop v8.0 software.

2. Impact Hammer Type 2303.

3. 6-Channel Spectrum Analyzer.

4. Accelerometer Type 4505 B.

\section{RESULTS AND DISCUSSION}

In the experimental model, the Frequency Response Function (FRF) is obtained by applying an impact test on uncracked and five different depth of crack that is $2 \mathrm{~mm}, 4 \mathrm{~mm}$, $6 \mathrm{~mm}, 8 \mathrm{~mm}$ and $10 \mathrm{~mm}$. The impact will be applied three times on each crack. Acceptance readings for data block depend to Frequency Response Function (FRF) plotting.

\section{For un-cracked shaft:}

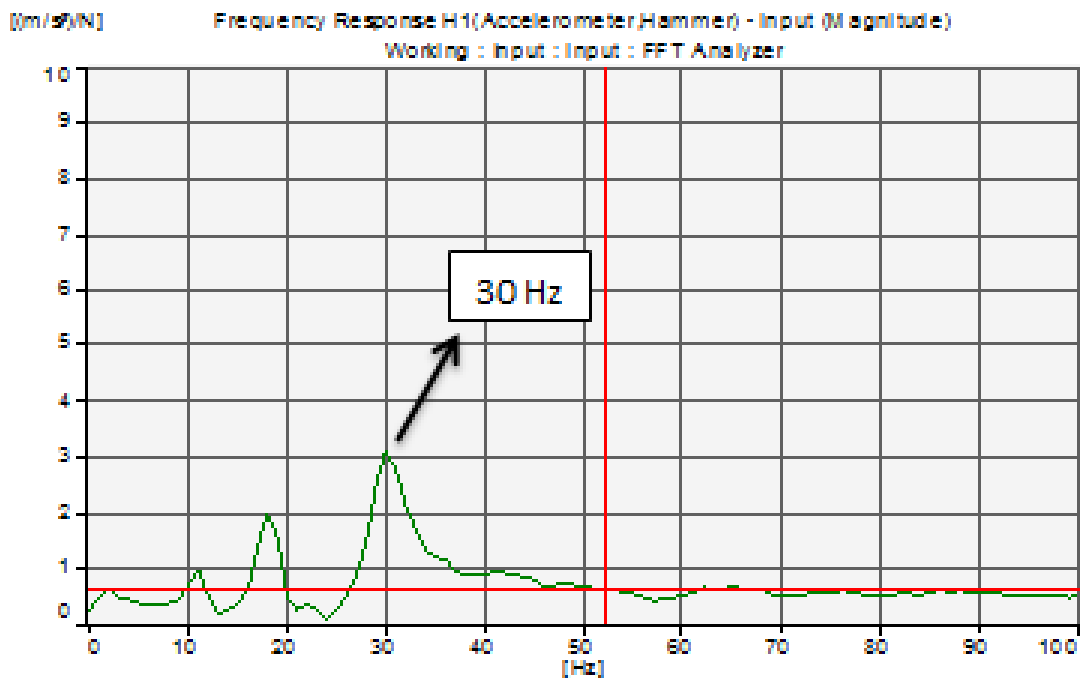

Fig. 4 Frequency response function for un-cracked shaft

\section{Status}

\section{Averages: 3}

Overlo ad: $0.00 \%$

Maximum Value

$\mathrm{Y}=3.01\left(\mathrm{~m} / \mathrm{s}^{2}\right) / \mathrm{N}$

$X=30.00 \mathrm{~Hz}$ 
For 2 mm depth of cracked shaft:

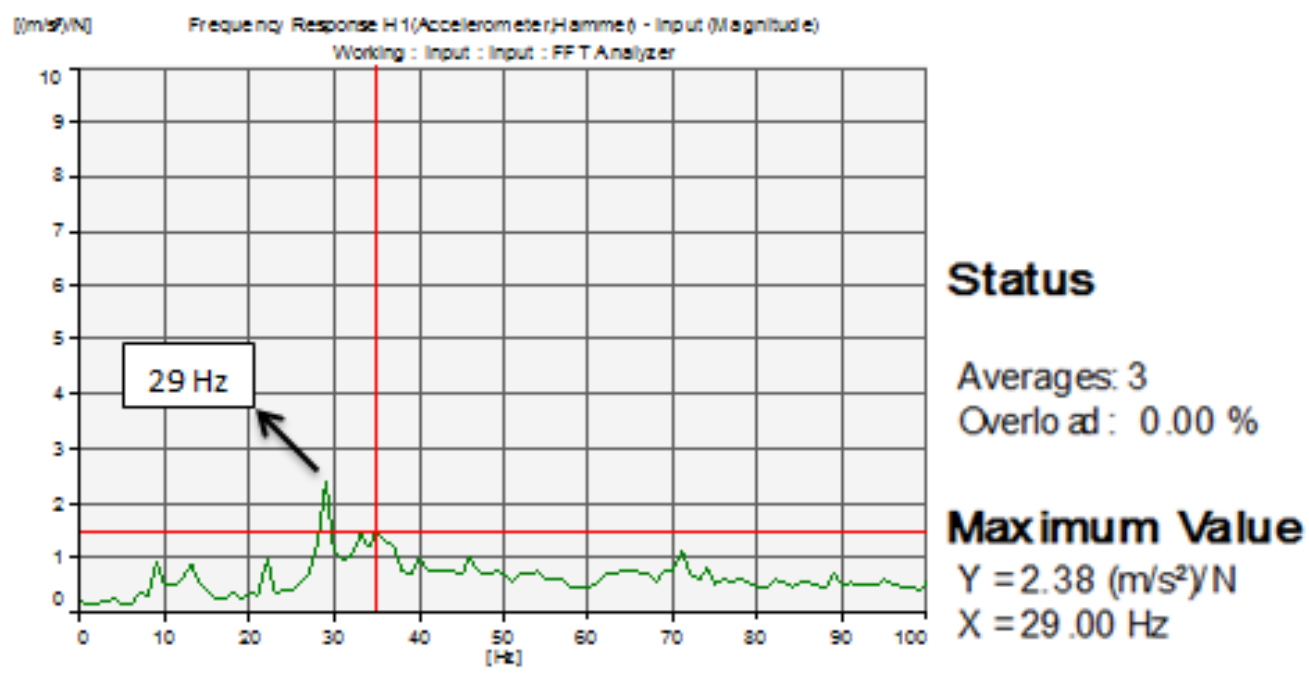

Fig. 5 Frequency response function for shaft with first crack

For 4 mm depth of cracked shaft:

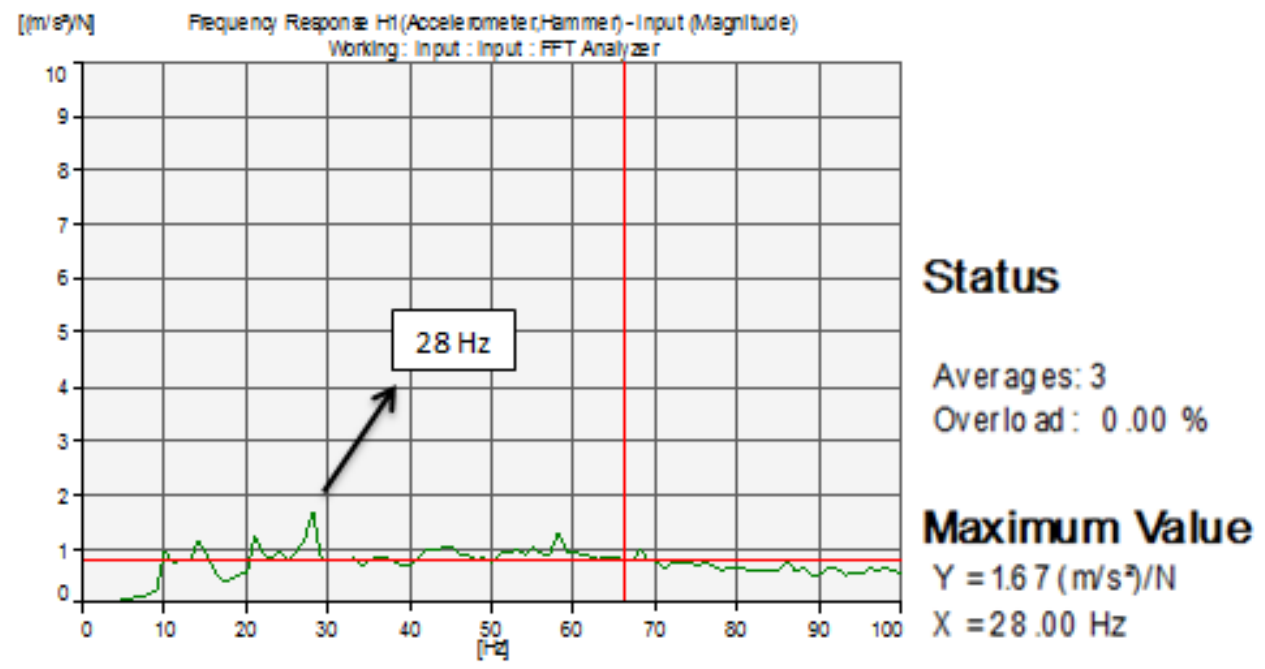

Fig. 6 Frequency response function for shaft with second crack

For 6 mm depth of cracked shaft:

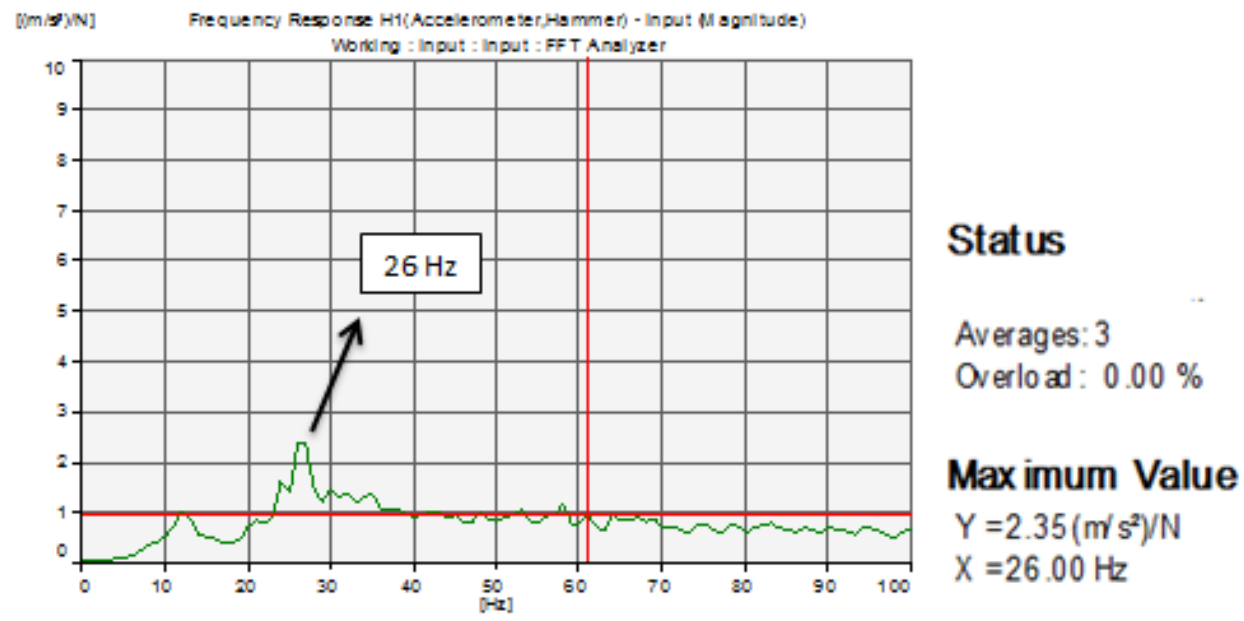

Fig. 7 Frequency response function for shaft with third crack 
For 8 mm depth of cracked shaft:

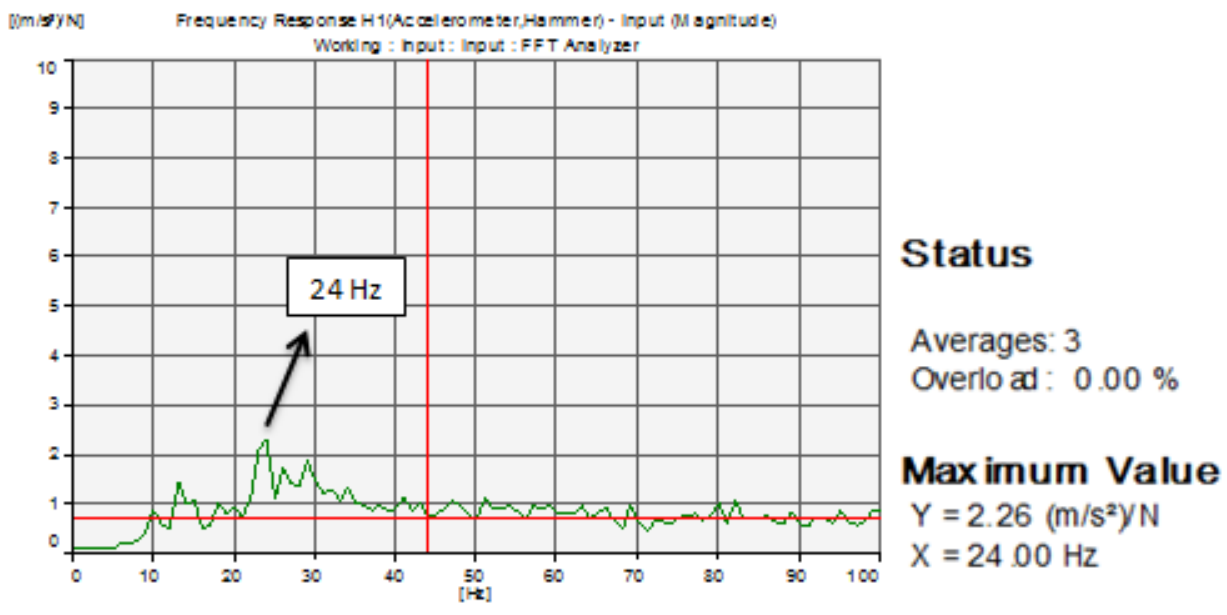

Fig. 8 Frequency response function for shaft with fourth crack

For $10 \mathrm{~mm}$ depth of cracked shaft:

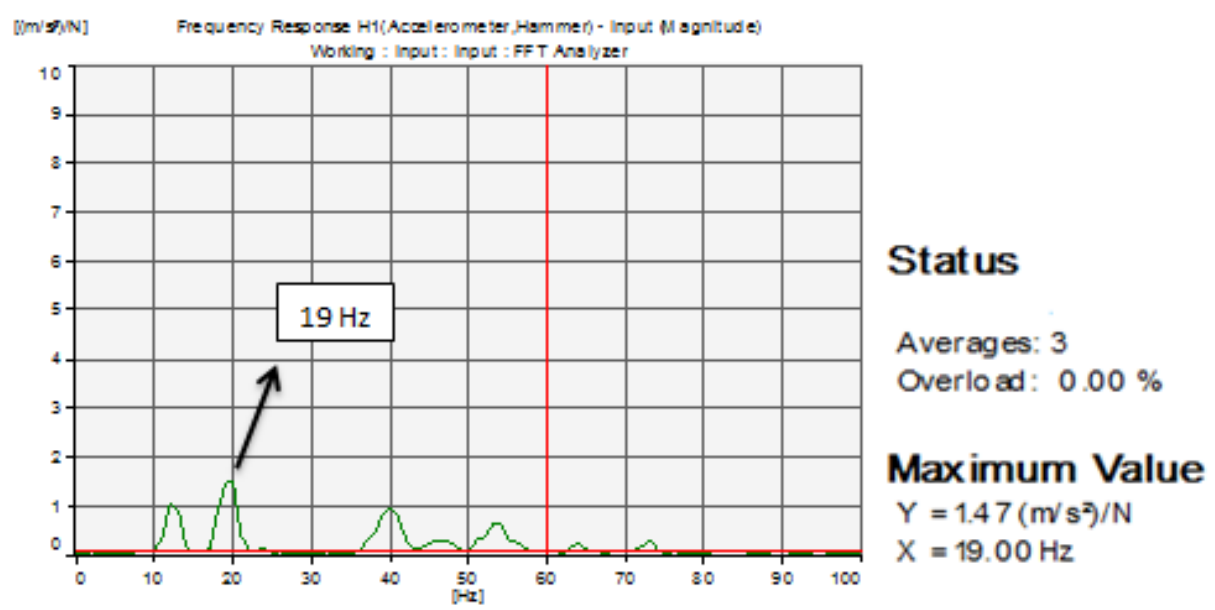

Fig. 9 Frequency response function for shaft with fifth crack

Based on the results above, the natural frequency for each condition which is un-cracked and cracked shaft were compared and it can be seen that the natural frequency showed an interesting pattern which as the depth of crack increasing, the natural decreasing.

$$
\omega_{\mathrm{n}}=\sqrt{\frac{k}{m}}
$$

The equation above shows the relationship between the stiffness, $(\mathrm{k})$ and angular frequency, $\left(\omega_{\mathrm{n}}\right)$ of the shaft[1]. The angular frequency, $\left(\omega_{\mathrm{n}}\right)$ is proportional to the stiffness, $(\mathrm{k})$ of the shaft. This explained why the natural frequency is decreasing, because as the stiffness of the shaft decreased, the natural frequency also decreased. This describes the damage occur on the structure greater as crack propagate which lead to reducing the stiffness of the structure.

\section{VALIDATION}

The result from the experiment is compared with other results. The comparisons have slightly differences since the specimen analyzed from previous study might not be identical with the specimen used in this experiment. The result is compared with the results from Numerical Analysis [8].

It is observed that the experimental method have minor deviation from result obtained by Numerical analysis. However, the results are in close agreement, showing that the decreasing natural frequency with increasing depth of crack. The table below shows the comparison between numerical analysis and experimental analysis. 
TABLE III

COMPARISON BETWEEN NUMERICAL ANALYSIS AND EXPERIMENTAL ANALYSIS

\begin{tabular}{|l|l|l|l|}
\hline $\begin{array}{c}\text { Depth of } \\
\text { crack }(\mathbf{m})\end{array}$ & \multicolumn{1}{|c|}{$\begin{array}{c}\text { Theoretical } \\
(\mathbf{H z})\end{array}$} & $\begin{array}{c}\text { Experimental } \\
(\mathbf{H z})\end{array}$ & $\begin{array}{c}\text { Error } \\
(\%)\end{array}$ \\
\hline 0 & 30.00 & 30.00 & - \\
\hline 0.002 & 29.80 & 29.00 & 1.36 \\
\hline 0.004 & 28.80 & 28.00 & 1.40 \\
\hline 0.006 & 26.94 & 26.00 & 1.77 \\
\hline 0.008 & 24.14 & 24.00 & 0.29 \\
\hline 0.01 & 18.54 & 19.00 & 1.22 \\
\hline Average of Error $(\%)=1.2 \%$ & & \\
\cline { 1 - 3 } &
\end{tabular}

\section{CONCLUSION}

In the end of this study, a conclusion can made through an observation and experiment about crack detection of shaft in the rotor system. Based on the result from the experiment, the main objective of this study has been achieved. It is showed that the natural frequency is decreasing as the depth of crack increasing. The results of this study is validate as the percentages of averages error between experimental and numerical analysis is about $1.2 \%$.

Based on the experiment, any cracks that exist on a shaft can be detected through changes in natural frequency of a structure. Each of the crack depth has its own natural frequency. Every excitation of force to the different depth of crack shows different natural frequency. Those cracks can cause the stiffness of the shaft to decrease and because of that, the natural frequency of the shaft will also be decrease. The reason is that natural frequency is proportional to the stiffness of the shaft. Therefore, this information can be helpful in monitoring vibration of rotating machinery.

\section{ACKNOWLEDGMENT}

The authors would like to thank the Universiti Selangor (UNISEL) that has give of sponsorship trough Internal Bestari Grant Research Programme. Our gratitude also goes to the members of Vibration Group Research of Mechanical Department, Faculty of Engineering, Universiti Selangor for their helpful discussion throughout the completion of this work.

\section{REFERENCES}

[1] A.D. Dimarogonas and S.A. Paipetis, (1983) Analytical Methods in Rotor Dynamics, Applied Science Publishers, London.

[2] A.D. Damarogonas and C.A. Papadopoulas, (1983), Vibration of Cracked Shaft in Bending, Journal of Sound and Vibration 91, 583593. http://dx.doi.org/10.1016/0022-460X(83)90834-9

[3] Bently, D.E., (1986), Vibration Analysis Techniques for Detecting and Diagnosing Shaft Cracks. Orbit, Bently Nevada 7(1).

[4] B. Grabowski, (1980), The Vibrational Behavior of a Turbine Rotor Containing a Transverse Crack, Transactions of the ASME 102, 141146. http://dx.doi.org/10.1115/1.3254704

[5] B.O. Dirr and B.K. Schmalhorst, (1987), Crack Depth Analysis of A Rotating Shaft by Vibration Measurements, 11th ASME Conference on Mechanical Vibration and Noise, Boston, pp. 607-614..
[6] R. Gasch, (1993), A Survey of the Dynamic Behavior of a Simple Rotating Shaft with a Transverse Crack, Journal of Sound and Vibration 160(2), 313-332. http://dx.doi.org/10.1006/jsvi.1993.1026

[7] Sekhar, A., \& Srinivas, B. (2003). Dynamics of cracked composite shafts. Journal of Reinforced Plastics and Composites, 22(7), 637-653 http://dx.doi.org/10.1177/073168403029358

[8] Nazirul Afiq, (2013), Numerical Analysis of Cracked Shaft Detection In Simple Model Rotor System, Faculty of Mechanical Engineering, Universiti Selangor 